\title{
The Use of Virtual and Augmented Reality by Older Adults: Potentials and Challenges
}

\author{
Alexander Seifert ${ }^{1,2 *}$ and Anna Schlomann ${ }^{3,4}$ \\ ${ }^{1}$ School of Social Work, University of Applied Sciences and Arts Northwestern Switzerland, Olten, Switzerland, ${ }^{2}$ Center of \\ Gerontology, University of Zurich, Zurich, Switzerland, ${ }^{3}$ Network Aging Research, Heidelberg University, Heidelberg, Germany, \\ ${ }^{4}$ Institute for Educational Sciences, Heidelberg University of Education, Heidelberg, Germany
}

Keywords: virtual reality, augmented reality, seniors, digital divide, inequality

\section{BACKGROUND}

The use of virtual reality (VR) and augmented reality (AR) promises many benefits for older adults, such as promoting a healthy lifestyle with health-related gaming, maintaining social contact via digital interfaces, supporting rehabilitation, and aiding in everyday life tasks (Czaja et al., 2019; Schlomann et al., 2019; Appel et al., 2020; Dermody et al., 2020). AR allows users to interact in new ways with their real environment, whereas VR provides them with new experiences in virtual environments. Although VR/AR user experiences may enhance well-being among older adults (e.g., Montana et al., 2020; Tuena et al., 2020), this group is largely neglected in current VR/AR participatory research (Lee et al., 2019; Sharifzadeh et al., 2020). Hence, while VR/AR tools have been developed for older adults, they were largely excluded from the development and design processes. Furthermore, gerontological aspects are rarely considered in this field.

Depending on their "real" environments (e.g., their living or social environments), older adults have different potentials and challenges when including VR/AR tools in their everyday lives. To access digital systems, individuals must accept, use, and develop skills related to these systems. However, because of the digital divide between younger and older adults, researchers should be aware of 1) the different use preferences of older adults and 2) their competencies and use levels (Seifert et al., 2019). Focusing on people aged 75 years and older, primarily those in retirement in Europe, we believe that these older adults may greatly benefit from the increased use of VR and AR, although we also acknowledge the existing digital divide. In this short opinion paper, we discuss the potential opportunities and barriers for older adults in the use of VR and AR and suggest how developers of VR/AR tools can consider their needs and preferences.

\section{POTENTIALS OF VIRTUAL REALITY AND AUGMENTED REALITY FOR OLDER ADULTS}

Although VR/AR technologies nowadays are scarce among the population aged 65 years and older, they may help these older adults with everyday life tasks (Wiederhold, 2020). The current COVID-19 pandemic has emphasized the potential of digital technologies in general and VR in particular to support social contact, interactive games and physical activities with VR-integrated exercise, and teleconsultations with doctors during stay-at-home mandates (Seifert et al., 2020a; Gao et al., 2020; Singh et al., 2020).

In our opinion, the potential of VR and AR seems high in five specific areas of life for older adults: 
- Real-world orientation: Since animated and real objects can be displayed simultaneously with standard smartphone technology, AR in particular can help users to navigate in new settings. For example, research in the use of VR and AR for tourism purposes is growing (Moro et al., 2019), and VR and AR might similarly be applied to benefit the orientation of older adults. AR may assist those individuals with mild memory issues or cognitive declines in navigating (un-) familiar areas by presenting them with information about a city or building directly on their smartphones.

- Education: VR and AR may also change learning methods and enhance intergenerational educational experiences in late life learning, which generally focuses on individual interests and social interaction. Although older adults are just as interested in education as younger adults, gerontological research shows that they have different learning speeds and orientations based on their long-life experiences (Duay and Byran, 2008). Therefore, learning in senior universities, for example., may be organized differently from work-related education (Formosa, 2019). Crucially, VR/AR technology can disconnect learning from physical environments, establish new forms of learning assistance via VR-based lessons, and include gamification elements (Daniela and Lytras, 2019; Simeone et al., 2019; Yoshimura and Borst, 2020).

- Health: The use of VR and AR in health promotion, such as psychotherapy and rehabilitation, can help to maintain health and well-being in older adults. The tools can contribute to maintaining older adults' motor abilities, fitness, cognition, balance, and memory (García-Betances et al., 2015; Corregidor-Sánchez et al., 2020; Gao et al., 2020). Moreover, VR intervention programs can be used to train cognitive and physical functions in older adults with mild cognitive impairments (D'Cunha et al., 2019; Thapa et al., 2020).

- Entertainment: AR-based games have gained popularity following the success of Pokémon GO and similar games (Laato et al., 2020; Schlomann and Rasche, 2020). Although these games target younger individuals and have not yet been researched in older populations, games that incorporate AR may also serve older adults, such as by providing them with leisure experiences (Schlomann et al., 2019).

- Social interaction: AR can support new forms of social interaction, such as those with avatars or embodied agents (Miller et al., 2019). Notably, older adults can have valuable social interactions when they play VR- or AR-based games together with other individuals (Santos et al., 2019). Older adults with mobility limitations (e.g., after a long hospital stay) can benefit from VR/AR social tools that allow them to see each other and VR/AR experiences that enable them to conduct activities (e.g., visiting a museum) together (Zielasko et al., 2020).

\section{DIGITAL DIVIDE ACROSS AGE GROUPS}

The digital divide between younger and older adults may prevent older adults from receiving the promised benefits of VR and AR in their everyday lives (Cotten, 2021). For example, although some older adults can use modern technologies like VR and AR to maintain social interaction during the current COVID-19 pandemic (Gao et al., 2020), these adults may also feel socially excluded when they lack the necessary skills and equipment to be included in these digital societies (Seifert et al., 2020b).

The global increase in internet access and the use of internetconnected devices has improved VR/AR accessibility in the general population. Nevertheless, older adults use the internet and smartphones less frequently than younger adults (Anderson, 2019). A survey across Switzerland and 16 European Union countries reported that only $53 \%$ of people aged 50 and older used the internet (König and Seifert, 2020). The survey also indicated that internet use among older adults was predicted by personal factors, such as age, gender, education, income, health, and prior experience with technology. In addition, an individual's level of technological socialization may also strongly influence their technology use. For instance, the Baby Boomer generation (born 1950-1969) did not grow up with digital technologies and has not been socialized into using them (Sackmann and Winkler, 2013). Furthermore, from a developmental perspective, people become more vulnerable (e.g., cognitive, visual, hearing, or body-strength limitations) as they grow older, especially the residents of long-term care facilities, who often have daily care needs and multiple medical comorbidities. Moreover, they must exert more effort than younger individuals to learn new technologies and must often overcome barriers arising from their limited cognitive, physical, financial, and social resources (Schulz et al., 2015; Mitzner et al., 2019).

Many of these concerns address the first level of the digital divide, which focuses on access to modern technologies, such as information and communications technologies, and impacts how individuals use them (Scheerder et al., 2017). The second level refers to the usage differences among those who employ new technologies, such as the digital inequality between skilled or active users and nonskilled or passive users. The third level deals with the varying benefits of technological interventions (e.g., wellbeing or social inclusion) for different individuals. In the VR/AR context, the digital divide thus refers not only to having access to VR/AR technologies but also to either actively or passively using VR/AR tools in everyday life contexts and if the technologies have positive outcomes for the older individual.

\section{GERONTOLOGICAL RECOMMENDATIONS FOR FURTHER DEVELOPMENTS}

Older adults face individualized challenges when using VR/AR tools in addition to those attributable to the general digital divide. Notably, older adults are not a homogeneous group of vulnerable people. To avoid stigmatization, VR/AR research should incorporate findings from gerontological research and involve diverse older adults in the development of tools at an early stage. Moreover, the following challenges should be considered in VR/ AR research and development to ensure that the unique perspectives of older adults are properly accounted for: 
- Classic methods: Because older adults mostly perform everyday life tasks in non-digital ways, technical solutions should clearly add value compared to offline solutions (Cotten, 2021). Likewise, VR and AR solutions should bolster their everyday activities (Roberts et al., 2019).

- Use and attitudes: As older adults are heterogeneous regarding their use of and attitudes toward technologies (Mitzner et al., 2010), technical developers of VR/AR tools should consider their individual needs and skill levels. Unfortunately, the current literature on the usefulness, acceptance, and effectiveness of VR and AR use among older adults is lacking (Lee et al., 2019).

- Abilities: Older adults vary in terms of their physical and cognitive abilities. For instance, not all older adults have mobility restrictions and visual or hearing losses, especially in the Third Age (65-80 years) (Baltes and Smith, 2003). Hence, developers should target groups with different tools or settings. For older adults with visual and hearing impairments, developers should adapt acoustically or visually challenging tools or consider their existing aids (e.g., avoid interference with hearing aid devices). Significantly, older adults with cognitive limitations (e.g., dementia) may be deceived if virtual worlds are presented to them as real, which should be avoided (D'Cunha et al., 2019).

- Cybersickness: Older adults may experience aspects of cybersickness, with symptoms including nausea, disorientation, and headaches (Davis et al., 2014). As older adults report cybersickness more frequently than younger adults in driving simulators (Keshavarz et al., 2018), they may also be more frequently affected by cybersickness in VR environments.

- Environments: The specific conditions of the living environments of older adults should be accounted for when developing a VR/AR tool. For example, to assist older adults living in long-term care facilities, developers should include care staff in the development of VR/AR tools and consider the higher care needs of the residents and the institutional infrastructure (e.g., internet accessibility).

Due to the novelty of the field, findings on the effectiveness of VR interventions are still limited (Gao et al., 2020). To reduce age-related inequalities in digital tools and thus increase participation among older adults, more money should be invested in training, educating, and supporting those older adults who face difficulties with VR/AR technologies. General

\section{REFERENCES}

Anderson, M. (2019). Mobile Technology and Home Broadband 2019. Available at: https://www.pewresearch.org/internet/wp-content/uploads/sites/9/2019/06/ PI_2019.06.13_Mobile-Technology-and-Home-Broadband_FINAL2.pdf (Accessed December 8, 2020).

Appel, L., Appel, E., Bogler, O., Wiseman, M., Cohen, L., Ein, N., et al. (2020). Older Adults with Cognitive And/or Physical Impairments Can Benefit from Immersive Virtual Reality Experiences: a Feasibility Study. Front. Med. 6, 329. doi:10.3389/fmed.2019.00329 recommendations are available to address technological development issues for older people (Cotten et al., 2016; Czaja et al., 2019), and they should be used and adapted for the special cases of VR and AR. There is emerging evidence of design recommendations for specific VR/AR technologies, such as those that address medication management (Guerrero et al., 2019) or exercise (Eisapour et al., 2018).

Crucially, the developers of VR/AR tools should closely examine how different designs and forms of content can be tailored to encourage trust and facilitate use among different groups of older users. Namely, they should address each group's interests. In the context of serious games, backstory, realism, interaction, and narrative elements can foster game-based learning experiences (Ravyse et al., 2017). Future studies should examine whether this also applies to older adults and VR/AR applications. If developers consider the end users in participatory research (i.e., research that includes the end users early and equally in the process of tool development), this increases the acceptance, usage, and effectiveness of their tools (Merkel and Kucharski, 2019). Therefore, older adults should be included in participatory research before developing digital solutions that target them. After developing a tool, it is also important to invest time in educating older adults on its use. A support hotline and contact partner can assist older participants when necessary.

\section{CONCLUSION}

We believe that VR and AR offer unique and innovative opportunities for older adults. Older adults, their relatives, and their professional caregivers can take advantage of these tools to improve their daily lives. However, the use of technology can be challenging, especially when older adults lack access to new tools or digital skills. Developers, practitioners, and researchers in the field must acknowledge digital inequalities and provide older adults with training tools, support services, and digital solutions that consider their heterogeneous backgrounds and needs.

\section{AUTHOR CONTRIBUTIONS}

All authors listed have made a substantial, direct, and intellectual contribution to the work and approved it for publication.

Baltes, P. B., and Smith, J. (2003). New Frontiers in the Future of Aging: From Successful Aging of the Young Old to the Dilemmas of the Fourth Age. Gerontology 49, 123-135. doi:10.1159/000067946

Corregidor-Sánchez, A.-I., Segura-Fragoso, A., Criado-Álvarez, J.-J., RodríguezHernández, M., Mohedano-Moriano, A., and Polonio-López, B. (2020). Effectiveness of Virtual Reality Systems to Improve the Activities of Daily Life in Older People. Int. J. Environ. Res. Public Health 17, 6283. doi:10.3390/ ijerph 17176283

Cotten, S. R. (2021). "Technologies and Aging: Understanding Use, Impacts, and Future Needs," in In Handbook of Aging and the Social Sciences. Editors D. Carr and K. F. Ferraro (New York: Academic Press). 
Cotten, S. R., Yost, E. A., Berkowsky, R. W., Winstead, V., and Anderson, W. A. (2016). Designing Technology Training for Older Adults in Continuing Care Retirement Communities. Boca Raton, FL: CRC Press. doi:10.1201/ 9781315382463

Czaja, S. J., Boot, W. R., Charness, N., and Rogers, W. A. (2019). Designing for Older Adults: Principles and Creative Human Factors Approaches. Boca Raton, FL: CRC Press.

Daniela, L., and Lytras, M. D. (2019). Editorial: Themed Issue on Enhanced Educational Experience in Virtual and Augmented Reality. Virtual Real 23, 325-327. doi:10.1007/s10055-019-00383-z

Davis, S., Nesbitt, K., and Nalivaiko, E. (2014). A Systematic Review of Cybersickness, in In Proceedings of the 2014 Conference on Interactive Entertainment IE2014. New York, NY, December 2, 2014 (Association for Computing Machinery), 1-9. doi:10.1145/2677758.2677780

D’Cunha, N. M., Nguyen, D., Naumovski, N., McKune, A. J., Kellett, J., Georgousopoulou, E. N., et al. (2019). A Mini-Review of Virtual RealityBased Interventions to Promote Well-Being for People Living with Dementia and Mild Cognitive Impairment. Gerontology 65, 430-440. doi:10. 1159/000500040

Dermody, G., Whitehead, L., Wilson, G., and Glass, C. (2020). The Role of Virtual Reality in Improving Health Outcomes for Community-Dwelling Older Adults: Systematic Review. J. Med. Internet Res. 22, e17331. doi:10.2196/17331

Duay, D. L., and Bryan, V. C. (2008). Learning in Later Life: What Seniors Want in a Learning Experience. Educ. Gerontol. 34, 1070-1086. doi:10.1080/ 03601270802290177

Eisapour, M., Cao, S., Domenicucci, L., and Boger, J. (2018). "Participatory Design of a Virtual Reality Exercise for People with Mild Cognitive Impairment," in Extended Abstracts of the 2018 CHI Conference on Human Factors in Computing Systems (Montreal, QC: ACM), Montreal, QC, Canada, April 20, 2018, 1-9. doi:10.1145/3170427.3174362

Formosa, M. (2019). "Active Ageing through Lifelong Learning: The University of the Third Age," in In the University of the Third Age and Active Ageing International Perspectives on Aging. Editor M. Formosa (Cham: Springer International Publishing), 3-18. doi:10.1007/978-3-030-21515-6_1

Gao, Z., Lee, J. E., McDonough, D. J., and Albers, C. (2020). Virtual Reality Exercise as a Coping Strategy for Health and Wellness Promotion in Older Adults during the COVID-19 Pandemic. J. Clin. Med. 9, 1986. doi:10.3390/ jcm9061986

García-Betances, R. I., Arredondo Waldmeyer, M. T., Fico, G., and CabreraUmpiérrez, M. F. (2015). A Succinct Overview of Virtual Reality Technology Use in Alzheimer's Disease. Front. Aging Neurosci. 7, 80. doi:10.3389/fnagi. 2015.00080

Guerrero, E., Lu, M.-H., Yueh, H.-P., and Lindgren, H. (2019). Designing and Evaluating an Intelligent Augmented Reality System for Assisting Older Adults' Medication Management. Cogn. Syst. Res. 58, 278-291. doi:10.1016/j.cogsys. 2019.07.001

Keshavarz, B., Ramkhalawansingh, R., Haycock, B., Shahab, S., and Campos, J. L. (2018). Comparing Simulator Sickness in Younger and Older Adults during Simulated Driving under Different Multisensory Conditions. Transp. Res. Part. F Traffic Psychol. Behav. 54, 47-62. doi:10.1016/j.trf.2018.01.007

König, R., and Seifert, A. (2020). From Online to Offline and Vice Versa: Change in Internet Use in Later Life across Europe. Front. Sociol. 5, 1-12. doi:10.3389/fsoc. 2020.00004

Laato, S., Hyrynsalmi, S., Rauti, S., Islam, A. K. M. N., and Laine, T. H. (2020). Location-based Games as Exergames - from Pokémon to the Wizarding World. Int. J. Serious Games 7, 79-95. doi:10.17083/ijsg.v7i1.337

Lee, L. N., Kim, M. J., and Hwang, W. J. (2019). Potential of Augmented Reality and Virtual Reality Technologies to Promote Wellbeing in Older Adults. Appl. Sci. 9, 3556. doi:10.3390/app9173556

Merkel, S., and Kucharski, A. (2019). Participatory Design in Gerontechnology: a Systematic Literature Review. The Gerontologist 59, e16-e25. doi:10.1093/ geront/gny034

Miller, M. R., Jun, H., Herrera, F., Yu Villa, J., Welch, G., and Bailenson, J. N. (2019). Social Interaction in Augmented Reality. PLOS ONE 14, e0216290. doi:10.1371/journal.pone.0216290

Mitzner, T. L., Boron, J. B., Fausset, C. B., Adams, A. E., Charness, N., Czaja, S. J., et al. (2010). Older Adults Talk Technology: Technology Usage and Attitudes. Comput. Hum. Behav. 26, 1710-1721. doi:10.1016/j.chb.2010.06.020
Mitzner, T. L., Savla, J., Boot, W. R., Sharit, J., Charness, N., Czaja, S. J., et al. (2019). Technology Adoption by Older Adults: Findings from the PRISM Trial. The Gerontologist 59, 34-44. doi:10.1093/geront/gny113

Montana, J. I., Matamala-Gomez, M., Maisto, M., Mavrodiev, P. A., Cavalera, C. M., Diana, B., et al. (2020). The Benefits of Emotion Regulation Interventions in Virtual Reality for the Improvement of Wellbeing in Adults and Older Adults: A Systematic Review. JCM 9, 500. doi:10.3390/jcm9020500

Moro, S., Rita, P., Ramos, P., and Esmerado, J. (2019). Analysing Recent Augmented and Virtual Reality Developments in Tourism. J. Hosp. Tour. Technol. 10, 571-586. doi:10.1108/JHTT-07-2018-0059

Ravyse, W. S., Seugnet Blignaut, A., Leendertz, V., and Woolner, A. (2017). Success Factors for Serious Games to Enhance Learning: a Systematic Review. Virtual Real 21, 31-58. doi:10.1007/s10055-016-0298-4

Roberts, A. R., De Schutter, B., Franks, K., and Radina, M. E. (2019). Older Adults' Experiences with Audiovisual Virtual Reality: Perceived Usefulness and Other Factors Influencing Technology Acceptance. Clin. Gerontol. 42, 27-33. doi:10. 1080/07317115.2018.1442380

Sackmann, R., and Winkler, O. (2013). Technology Generations Revisited: the Internet Generation. Gerontechnology 11, 493-503. doi:10.4017/gt.2013.11.4. 002.00

Santos, L. H. D. O., Okamoto, K., Funghetto, S. S., Cavalli, A. S., Hiragi, S., Yamamoto, G., et al. (2019). Effects of Social Interaction Mechanics in Pervasive Games on the Physical Activity Levels of Older Adults: Quasi-Experimental Study. JMIR Serious Games 7, e13962. doi:10.2196/13962

Scheerder, A., van Deursen, A., and van Dijk, J. (2017). Determinants of Internet Skills, Uses and Outcomes: a Systematic Review of the Second- and ThirdLevel Digital Divide. Telemat. Inform. 34, 1607-1624. doi:10.1016/j.tele.2017. 07.007

Schlomann, A., and Rasche, P. (2020). Same but Different: a Comparison of Players' Perceptions and Motivational Factors in Two Commercially Available AR Games. Comput. Games J. 9, 383-399. doi:10.1007/s40869020-00114-4

Schlomann, A., Rasche, P., Seifert, A., Schäfer, K., Wille, M., Bröhl, C., et al. (2019). "Augmented Reality Games for Health Promotion in Old Age," in In Augmented Reality Games II. Editor V. Geroimenko (Cham: Springer International Publishing), 159-177. doi:10.1007/978-3-030-15620-6_7

Schulz, R., Wahl, H.-W., Matthews, J. T., De Vito Dabbs, A., Beach, S. R., and Czaja, S. J. (2015). Advancing the Aging and Technology Agenda in Gerontology. The Gerontologist 55, 724-734. doi:10.1093/geront/gnu071

Seifert, A., Batsis, J. A., and Smith, A. C. (2020a). Telemedicine in Long-Term Care Facilities during and beyond COVID-19: Challenges Caused by the Digital Divide. Front. Public Health 8, 601595. doi:10.3389/fpubh.2020. 601595

Seifert, A., Cotten, S. R., and Xie, B. (2020b). A Double Burden of Exclusion? Digital and Social Exclusion of Older Adults in Times of COVID-19. J. Gerontol. Ser. B 76, e99-e103. doi:10.1093/geronb/gbaa098

Seifert, A., Reinwand, D. A., and Schlomann, A. (2019). Designing and Using Digital Mental Health Interventions for Older Adults: Being Aware of Digital Inequality. Front. Psychiatry 10, 568. doi:10.3389/fpsyt.2019.00568

Sharifzadeh, N., Kharrazi, H., Nazari, E., Tabesh, H., Edalati Khodabandeh, M., Heidari, S., et al. (2020). Health Education Serious Games Targeting Health Care Providers, Patients, and Public Health Users: Scoping Review. JMIR Serious Games 8, e13459. doi:10.2196/13459

Simeone, A. L., Speicher, M., Molnar, A., Wilde, A., and Daiber, F. (2019). LIVE: the Human Role in Learning in Immersive Virtual Environments. in Symposium on Spatial User Interaction (New Orleans LA USA: ACM), New Orleans, LA, October 19, 2019, 1-11. doi:10.1145/3357251.3357590

Singh, R. P., Javaid, M., Kataria, R., Tyagi, M., Haleem, A., and Suman, R. (2020). Significant Applications of Virtual Reality for COVID-19 Pandemic. Diabetes Metab. Syndr. Clin. Res. Rev. 14, 661-664. doi:10.1016/j.dsx.2020.05.011

Thapa, N., Park, H. J., Yang, J.-G., Son, H., Jang, M., Lee, J., et al. (2020). The Effect of a Virtual Reality-Based Intervention Program on Cognition in Older Adults with Mild Cognitive Impairment: a Randomized Control Trial. J. Clin. Med. 9, 1283. doi: $10.3390 /$ jcm 9051283

Tuena, C., Pedroli, E., Trimarchi, P. D., Gallucci, A., Chiappini, M., Goulene, K., et al. (2020). Usability Issues of Clinical and Research Applications of Virtual Reality in Older People: A Systematic Review. Front. Hum. Neurosci. 14, 93. doi:10.3389/fnhum.2020.00093 
Wiederhold, B. K. (2020). How Virtual Reality Is Changing the Reality of Aging. Cyberpsychology Behav. Soc. Netw. 23, 141-142. doi:10.1089/cyber.2020. 29176.bkw

Yoshimura, A., and Borst, C. W. (2020). "Remote Instruction in Virtual Reality: a Study of Students Attending Class Remotely from Home with VR Headsets," in Mensch und Computer 2020 - Workshopband(Bonn: Gesellschaft für Informatik e.V.). Editors C. Hansen, A. Nürnberger, and B. Preim Available at: http://dl.gi. de/handle/20.500.12116/33533 (Accessed December 4, 2020). doi:10.1145/ 3385956.3422124

Zielasko, D., Feld, N., Flemming, C., Lungershausen, P., Morgenthal, A., Schmitz, S. D., et al. (2020). "Towards Preservation and Availability of Heterogeneous Cultural Heritage Research Data via a Virtual Museum," in GI VR/AR Workshop(Trier: Gesellschaft für Informatik e.V.). Editors B. Weyers,
C. Lürig, and D. Zielasko Available at: http://dl.gi.de/handle/20.500.12116/ 33439 (Accessed December 4, 2020). doi:10.1109/vrw50115.2020.00067

Conflict of Interest: The authors declare that the research was conducted in the absence of any commercial or financial relationships that could be construed as a potential conflict of interest.

Copyright (C) 2021 Seifert and Schlomann. This is an open-access article distributed under the terms of the Creative Commons Attribution License (CC BY). The use, distribution or reproduction in other forums is permitted, provided the original author(s) and the copyright owner(s) are credited and that the original publication in this journal is cited, in accordance with accepted academic practice. No use, distribution or reproduction is permitted which does not comply with these terms. 